\title{
PENERAPAN METODE FORWARD CHAINING PADA APLIKASI PEMILIHAN KAMPUS DI KOTA MALANG BAGI CALON MAHASISWA
}

\author{
Heliani Dessy ${ }^{1}$, Amak Yunus ${ }^{2}$, Wahyudi Priyanto ${ }^{3}$. \\ Teknik Informatika, Universitas Kanjuruhan Malang ${ }^{123}$ \\ dessyheliani@gmail.com¹, amakyunus@unikama.ac.id ${ }^{2}$,wahyudi@unikama.ac.id ${ }^{3}$
}

\begin{abstract}
Abstrak. Terdapat 52 kampus di kota Malang dan pertumbuhan mahasiswa baru rata-rata meningkat sekitar 5-10\% setiap tahun. Dalam memilih kampus tentu banyak pertimbangan seperti biaya, jurusan, akreditasi, kategori PTN/PTS, status, dan jarak yang harus ditempuh. Calon mahasiswa yang akan kuliah di kota Malang tidak hanya berasal dari kota Malang saja tetapi banyak juga yang berasal dari luar daerah bahkan luar negeri. Calon Mahasiswa yang berasal dari luar kota Malang tentu belum mengetahui kampus mana saja yang memiliki jurusan serta akreditasi yang bagus dan dengan biaya yang terjangkau, maka diperlukan sebuah solusi melalui penerapan metode forward chaining pada sebuah aplikasi, Melalui penerapan metode ini dapat membantu dan mempermudah calon mahasiswa mencari kampus yang tepat sesuai kriteria yang diinginkan. Tujuan penelitian ini adalah membuat sebuah aplikasi pemilihan kampus untuk mempermudah calon mahasiswa mencari dan memilih kampus di kota Malang menggunakan jenis data kualitatif. Melalui pengujian User Acceptance Test terhadap 36 orang responden memperoleh nilai rata-rata $89 \%$ responden menyatakan setuju adanya aplikasi ini dengan metode Forward Chaining.
\end{abstract}

Kata Kunci : Forward Chaining, Pemilihan Kampus, Sistem Informasi.

\section{PENDAHULUAN}

Calon mahasiswa yang tidak lolos mendaftar ke kampus yang mereka tuju tentunya akan mencari kampus yang memiliki program studi yang sama seperti pada awal mereka mendaftar di kampus sebelumnya. Dalam memilih kampus tentu banyak pertimbangan seperti program studi, akreditasi program studi, akreditasi kampus, kategori PTN/PTS, status, biaya dan jarak kampus yang harus ditempuh oleh calon mahasiswa. Maka dibuat sebuah aplikasi melalui penerapan metode forward chaining untuk membantu dan mempermudah calon mahasiswa mencari dan memilih kampus yang tepat sesuai kriteria yang diinginkan.

\section{METODE PENELITIAN}

Jenis penelitian yang digunakan adalah kualitatif dengan instrumen pengumpulan data yaitu melalui wawancara dan survei kuesioner. Proses atau alur Forward chaining adalah menggunakan aturan If and Then untuk mencapai sebuah konklusi yang diawali dengan fakta. Ada beberapa kriteria yang menjadi parameter pada penelitian ini yaitu biaya SPP, DPP, jurusan , akreditasi jurusan, status kampus, kategori PTN/PTS dan nama kampus sebagai sebuah konklusi. Berikut adalah tabel parameter dan kaidah produksi dari Forward Chaining :

Tabel 1. Parameter

\begin{tabular}{llllcccl}
\hline No & DPP & SPP & Jurusan & Akreditasi & Status & kategori & $\begin{array}{l}\text { Nama } \\
\text { Kampus }\end{array}$ \\
\hline 1 & Rp.6.500.000 & Rp.2.800.000 & $\begin{array}{l}\text { S1 Teknik } \\
\text { Informatika }\end{array}$ & B & Aktif & Swasta & STIMATA \\
\hline 2 & Rp.5.500.000 & Rp.2.500.000 & $\begin{array}{l}\text { S1 Pendidikan } \\
\text { Bahasa dan } \\
\text { Sastra }\end{array}$ & B & Aktif & Swasta & $\begin{array}{l}\text { Univ. } \\
\end{array}$ \\
& & & & & $\begin{array}{l}\text { Widyadhar } \\
\text { ma }\end{array}$
\end{tabular}


Indonesia

\begin{tabular}{|c|c|c|c|c|c|c|c|}
\hline 3 & $\begin{array}{l}\text { Rp.9.000.000 } \\
\text {; }\end{array}$ & $\begin{array}{l}\text { Rp.2.500.000 } \\
\text {; }\end{array}$ & S1 Manajemen & $\mathrm{B}$ & Aktif & Swasta & UNIKAMA \\
\hline 4 & $\begin{array}{l}\text { Rp.10.000.00 } \\
0\end{array}$ & $\begin{array}{l}\text { Rp.1.250.000 } \\
;\end{array}$ & $\begin{array}{l}\text { S1 Teknik } \\
\text { Informatika }\end{array}$ & $\mathrm{B}$ & Aktif & Swasta & STIKI \\
\hline 5 & $\begin{array}{l}\text { Rp.9.000.000 } \\
;\end{array}$ & $\begin{array}{l}\text { Rp.3.250.000 } \\
\text {; }\end{array}$ & $\begin{array}{l}\text { S1 Pendidikan } \\
\text { Bahasa dan } \\
\text { Sastra } \\
\text { Indonesia }\end{array}$ & $\mathrm{A}$ & Aktif & Swasta & UNISMA \\
\hline 6 & $\begin{array}{l}\text { Rp.10.000.00 } \\
0\end{array}$ & $\begin{array}{l}\text { Rp.3.200.000 } \\
;\end{array}$ & S1 Manajemen & $\mathrm{B}$ & Aktif & Swasta & $\begin{array}{l}\text { Univ. } \\
\text { Gajayana }\end{array}$ \\
\hline 7 & $\begin{array}{l}\text { Rp.15.000.00 } \\
0\end{array}$ & Rp.1.900.000 & $\begin{array}{l}\text { S1 Teknik } \\
\text { Informatika }\end{array}$ & B & Aktif & Swasta & ITN \\
\hline 8 & $\begin{array}{l}\text { Rp.12.500.00 } \\
0 ;\end{array}$ & $\begin{array}{l}\text { Rp.3.500.000 } \\
\text {; }\end{array}$ & S1 Manajemen & $\mathrm{A}$ & Aktif & Negeri & UIN \\
\hline 9 & $\begin{array}{l}\text { Rp.15.000.00 } \\
0 ;\end{array}$ & $\begin{array}{l}\text { Rp.7.000.000 } \\
\text {; }\end{array}$ & $\begin{array}{l}\text { D-IV Teknik } \\
\text { Informatika }\end{array}$ & B & Aktif & Negeri & $\begin{array}{l}\text { POLINEM } \\
\text { A }\end{array}$ \\
\hline 10 & $\begin{array}{l}\text { Rp.12.750.00 } \\
0 ;\end{array}$ & $\begin{array}{l}\text { Rp.2.250.000 } \\
;\end{array}$ & $\begin{array}{l}\text { S1 Teknik } \\
\text { Informatika }\end{array}$ & B & Aktif & Negeri & UIN \\
\hline 11 & $\begin{array}{l}\text { Rp.12.000.00 } \\
0\end{array}$ & $\begin{array}{l}\text { Rp.4.100.000 } \\
\text {; }\end{array}$ & $\begin{array}{l}\text { S1 Pendidikan } \\
\text { Bahasa dan } \\
\text { Sastra } \\
\text { Indonesia }\end{array}$ & B & Aktif & Negeri & UM \\
\hline 12 & $\begin{array}{l}\text { Rp.18.200.00 } \\
0 ;\end{array}$ & $\begin{array}{l}\text { Rp.5.800.000 } \\
\text {; }\end{array}$ & $\begin{array}{l}\text { S1 Pendidikan } \\
\text { Bahasa dan } \\
\text { Sastra } \\
\text { Indonesia }\end{array}$ & B & Aktif & Swasta & UMM \\
\hline
\end{tabular}

Tabel 2. Kaidah Produksi Forward Chaining

\begin{tabular}{ll}
\hline No & \multicolumn{1}{c}{ Aturan } \\
\hline 1 & $\begin{array}{l}\text { If biaya DPP<10 juta dan status aktif and biaya SPP }<4 \text { juta and jurusan Teknik } \\
\text { Informatika and akreditasi B and kategori swasta then STIMATA }\end{array}$ \\
\hline 2 & $\begin{array}{l}\text { If biaya DPP<10 juta dan status aktif and biaya SPP<4 juta and jurusan Pendidikan } \\
\text { Bahasa Indonesia and akreditasi B and kategori swasta then }\end{array}$ \\
\hline 3 & $\begin{array}{l}\text { Universitas Wisnuwardhana } \\
\text { If biaya DPP<10 juta dan status aktif and biaya SPP<4 juta and jurusan manajemen } \\
\text { and akreditasi B and kategori swasta then Universitas Kanjuruhan Malang }\end{array}$ \\
\hline 4 & $\begin{array}{l}\text { If biaya DPP<10 juta dan status aktif and biaya SPP<4 juta and jurusan manajemen } \\
\text { and akreditasi B and kategori swasta then Universitas Kristen Cipta Wacana }\end{array}$ \\
\hline 5 & $\begin{array}{l}\text { If biaya DPP<10 juta dan status aktif and biaya SPP 4-8 juta and jurusan Teknik } \\
\text { Informatika and akreditasi B and kategori swasta then Sekolah Tinggi Informatika } \\
\text { dan Komputer Indonesia }\end{array}$ \\
\hline 6 & $\begin{array}{l}\text { If biaya DPP<10 juta dan status aktif and biaya SPP 4-8 juta and jurusan } \\
\text { Pendidikan Bahasa Indonesia and akreditasi A and kategori swasta then }\end{array}$ \\
\hline 7 & $\begin{array}{l}\text { If biaya DPP }<10 \text { juta dan status aktif and biaya SPP 4-8 juta and jurusan } \\
\text { Manajemen and akreditasi B and kategori negeri then Universitas Negeri Malang }\end{array}$ \\
\hline 8 & $\begin{array}{l}\text { If biaya DPP<10 juta dan status aktif and biaya SPP 4-8 juta and jurusan } \\
\text { manajemen and akreditasi B and kategori swasta then Universitas Gajayana }\end{array}$ \\
\hline 9 & $\begin{array}{l}\text { If biaya DPP } 10-20 \text { juta dan status aktif and biaya SPP <4 juta and jurusan } \\
\text { Teknik Informatika and akreditasi B and kategori swasta then Institut Teknologi } \\
\text { Nasional Malang }\end{array}$ \\
\hline 10 & $\begin{array}{l}\text { If biaya DPP 10 - 20 juta dan status aktif and biaya SPP <4 juta and jurusan } \\
\text { Teknik Informatika and akreditasi B and kategori swasta then Universitas }\end{array}$ \\
\hline
\end{tabular}


Kanjuruhan Malang

11 If biaya DPP 10 - 20 juta dan status aktif and biaya SPP <4 juta and jurusan Manajemen and akreditasi A and kategori Negeri then Universitas Islam Negeri Maulid Malang

12 If biaya DPP 10 - 20 juta dan status aktif and biaya SPP 4-8 juta and jurusan Teknik Informatika and kriteria B and kategori Negeri and Politeknik Negeri Malang

13 If biaya DPP 10 - 20 juta dan status aktif and biaya SPP 4-8 juta and jurusan Teknik Informatika and kriteria B and kategori Negeri and Universitas Islam Negeri Malang

\begin{tabular}{ll}
\hline 14 & $\begin{array}{l}\text { If biaya DPP } 10-20 \text { juta dan status aktif and biaya SPP 4-8 juta and jurusan } \\
\text { Pendidikan Bahasa Indonesia and akreditasi B and kategori Negeri then }\end{array}$ \\
& Universitas Negeri Malang \\
\hline 15 & $\begin{array}{l}\text { If biaya DPP } 10-20 \text { juta dan status aktif and biaya SPP 4-8 juta and jurusan } \\
\text { Pendidikan Bahasa Indonesia and kriteria B and kategori swasta and Universitas } \\
\text { Muhammadiyah Malang }\end{array}$ \\
\hline
\end{tabular}

Berikut ini adalah pohon keputusan forward chaining :

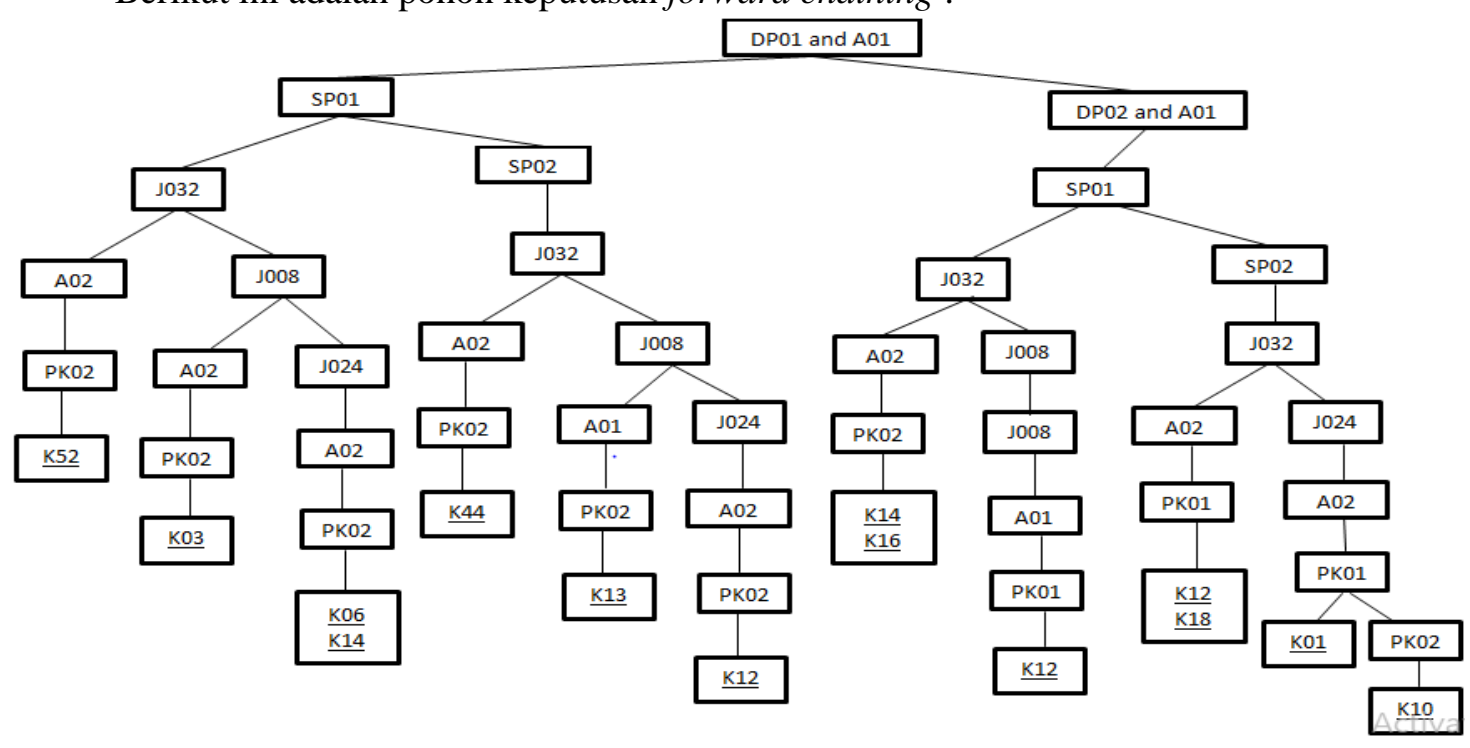

Gambar 2. Pohon Keputusan

Pada pohon keputusan diatas hanya biaya terendah dan menengah karena biaya merupakan fakor utama yang menjadi bahan pertimbangan bagi orang tua calon mahasiswa dalam memilih kampus, ketika calon mahasiswa mencari kampus pasti akan memilih range biaya terendah dan menengah.

\section{HASIL DAN PEMBAHASAN}

Perancangan system menggunakan Unified Modeling Language (UML). Mendeskripsikan penerapan forward chaining pada aplikasi pemilihan kampus di menu Cari Kampus. 


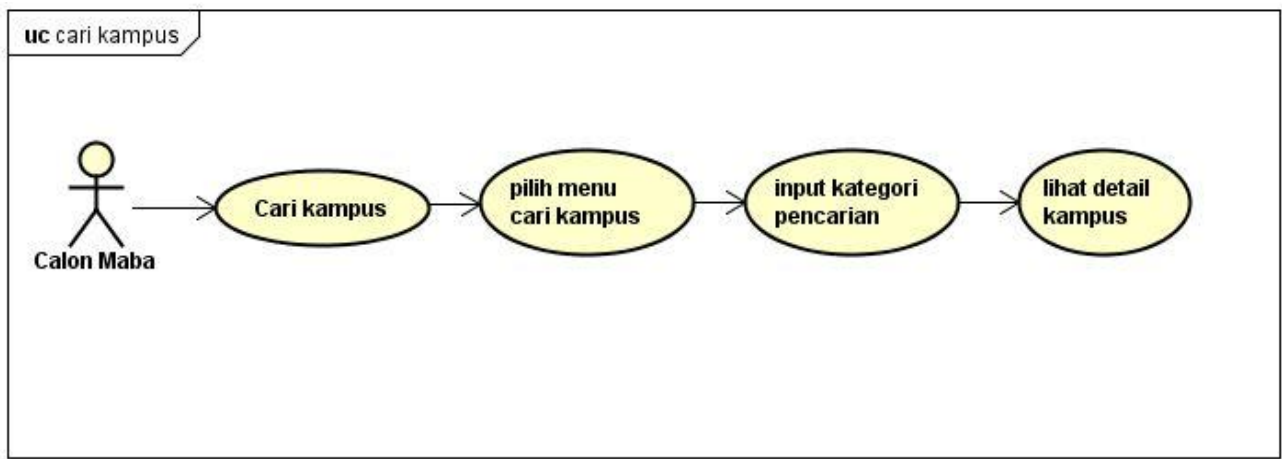

Gambar 2. Use Case Diagram Cari Kampus

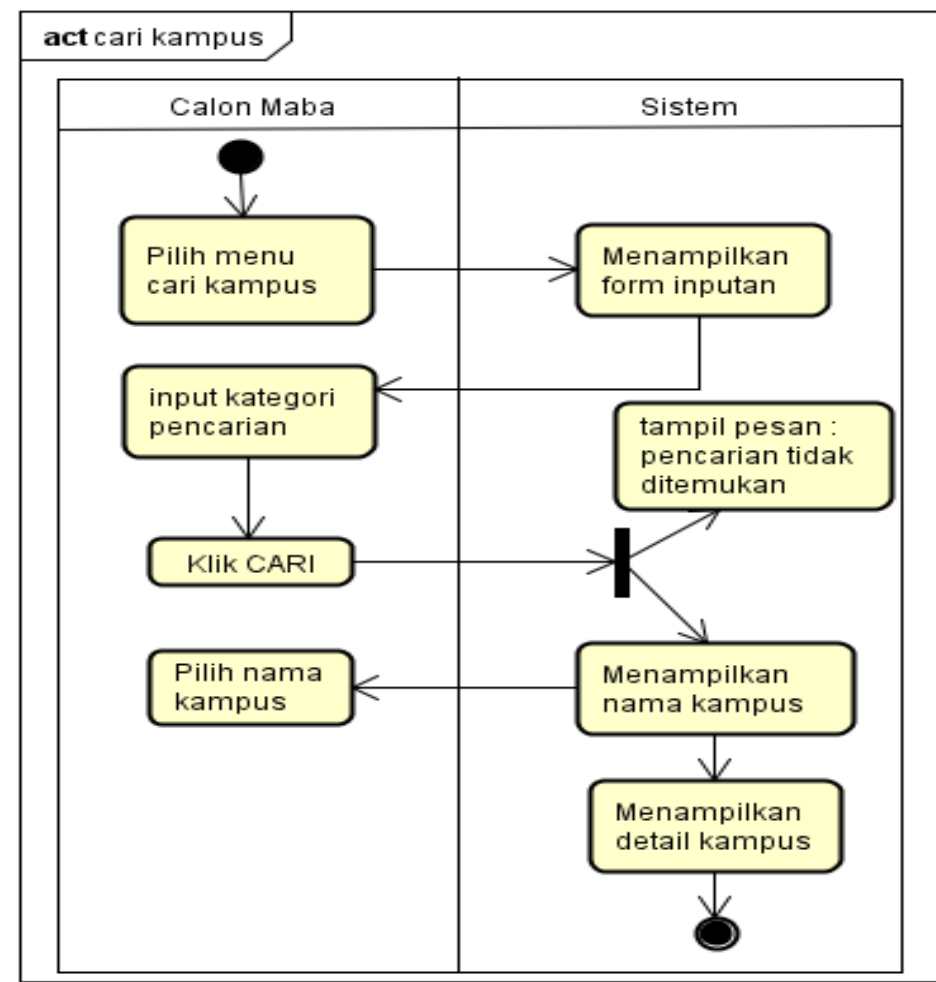

Gambar 3. Activity Diagram Cari Kampus

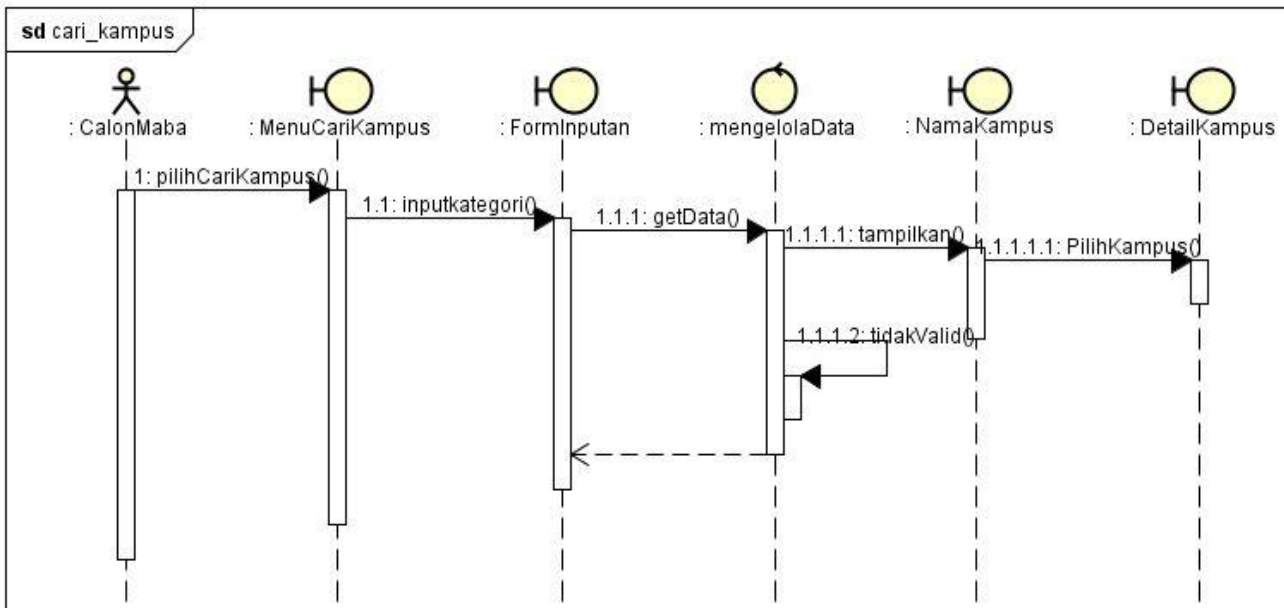

Gambar 4. Sequence Diagram Cari Kampus 


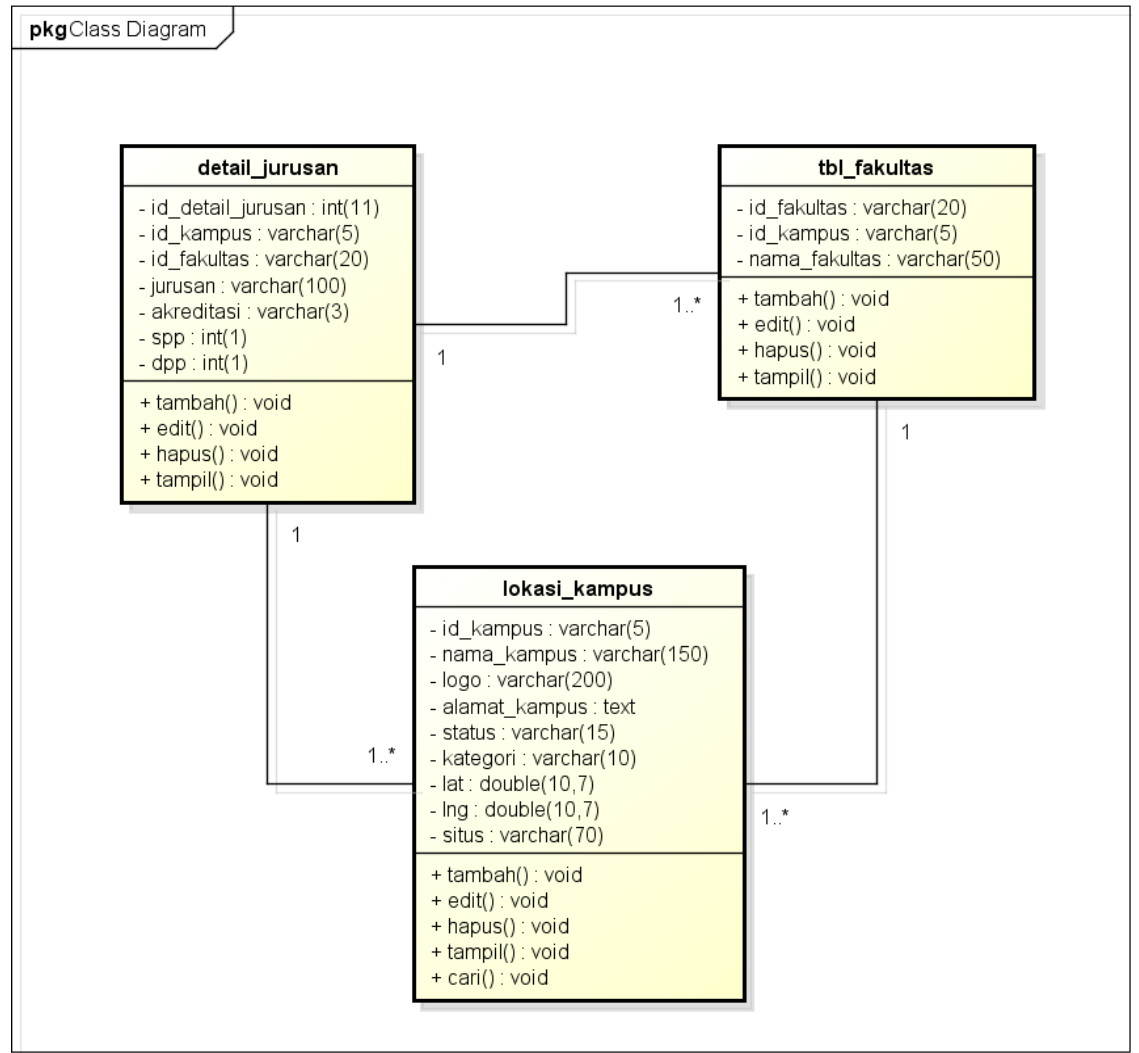

Gambar 5. Class Diagram

\section{Implementasi}

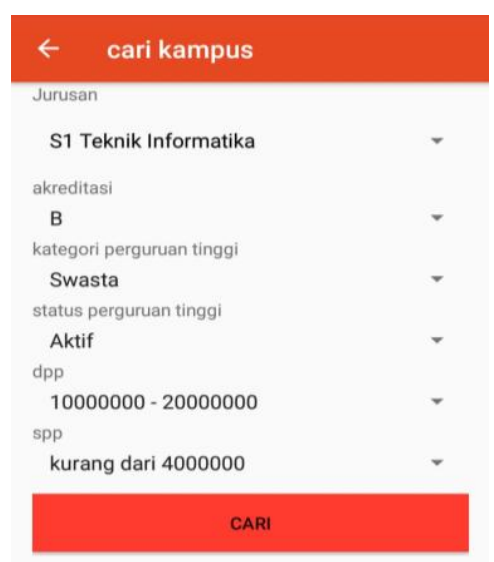

Gambar 6. Tampilan input cari kampus 


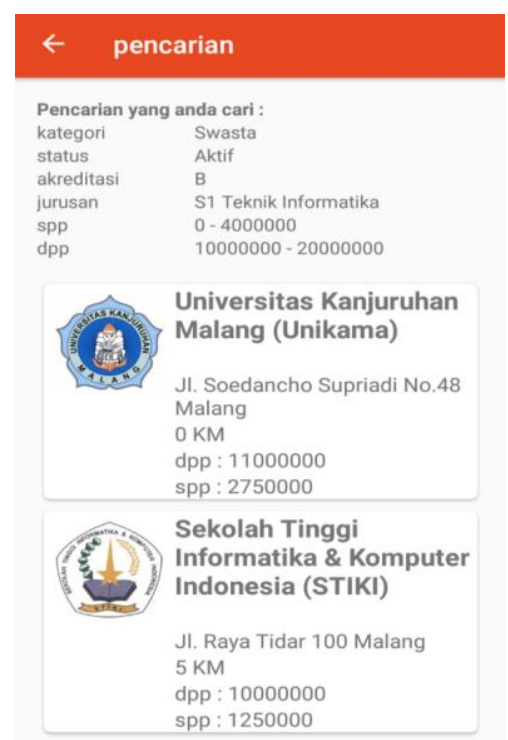

Gambar 7. Tampilan Hasil Cari Kampus

\section{Pembahasan Produk}

Berdasarkan hasil analisa User Acceptance Test(UAT) pada tabel 4.16, menunjukkan nilai rata-rata pada aspek sistem $89 \%$ menyatakan setuju bahwa aplikasi pemilihan kampus ini sudah memiliki tampilan yang menarik dan mudah digunakan. Pada aspek pengguna $89 \%$ menunjukkan setuju bahwa menu-menu pada aplikasi ini mudah dipahami, informasi yang diberikan dapat membantu pengguna dalam mencari kampus, dapat menjadi solusi dalam mencari kampus sesuai kriteria pengguna dan hasil yang ditampilkan sesuai dengan inputan pencarian. Pada aspek interaksi $91 \%$ menunjukkan bahwa pengguna mudah mengakses semua menu dan website kampus yang disediakan dapat diakses dengan baik.

\section{PENUTUP}

Berdasarkan hasil dari penelitian ini dan pembahasan dari Penerapan Metode Forward Chaining pada Aplikasi Pemilihan Kampus di Kota Malang bagi Calon Mahasiswa, aplikasi ini dapat membantu calon mahasiswa untuk memilih kampus di kota Malang dengan menggunakan Forward Chaining, karena calon mahasiswa dapat mencari kampus yang di inginkan dengan mudah. Melalui pengujian user acceptance test terhadap 36 orang responden yang mengisi kuesioner memperoleh nilai rata-rata $89 \%$ responden menyatakan setuju dengan adanya aplikasi pemilihan kampus dengan metode forward chaining. Oleh sebab itu peneliti menyimpulkan bahwa Aplikasi pemilihan kampus dapat memudahkan calon mahasiswa dalam mencari kampus yang sesuai dengan kriteria yang dicari dan metode Forward Chaining dapat diimplementasikan pada aplikasi ini berdasarkan keakuratan hasil responden $89 \%$ yang ditujukan pada pertanyaan nomor 3 sampai nomor 6 . Saran yang dapat diberikan antara lain: aplikasi pemilihan kampus bagi calon mahasiswa dapat dikembangkan lagi menggunakan metode lain;

menambahkan fitur berita prestasi yang sudah diraih oleh kampus tersebut; dan aplikasi dapat diakses di web dan semua smartphone. 


\section{DAFTAR PUSTAKA}

Agustina, R., \& Suprianto, D. 2018. Analisis Hasil Pemanfaatan Media Pembelajaran Interaktif. Universitas Kanjuruhan Malang; Politeknik Negeri Malang Volume 08 Nomor 02, Oktober Tahun 2018.

Aristoteles, M. F. 2017. Expert System of Chili Plant Disease Diagnosis using Forward Chaining Method on Android. (IJACSA) International Journal of Advanced Computer Science and Applications, .

Hidayatullah, P., \& Kawistra, J. K. (n.d.). Pemograman Web. [online] Available : https://developer.mozilla.org/enUS/docs/Learn/JavaScript/First_steps/What_is_Ja vaScript. [Accessed 20 Agustus 2019].

Json.org, "Pengenalan JSON.” [Online]. Available: http://www.json.org/jsonid.html. [Accessed: 25-Mar-2020].

MySql, P. W. 2011. M Rudianto Arief. Yogyakarta.

Nasional, U. 2003. Undang-Undang sistem pendidikan nasional. [online] Available : http://simkeu.kemdikbud.go.id/index.php/peraturan1/8-uu-undang-undang/12-uuno-20-tahun-2003-tentang-sistem-pendidikan-nasional

Pratama, F. A., Dipayana, B., \& Mukaromah, A. R. 2016. Perancangan Sistem Pakar Aplikasi Pencarian Rumah Makan Berbasis Android Menggunakan Metode Forward Chaining. STMIK AMIKOM Yogyakarta, 6-7 Februari 2016.

Rizki Wahyudi, M. R. 2016. Sistem Pakar E-Tourism Pada Dinas Pariwisata D.I.Y Menggunakan Metode Forward Chaining. Jurnal Ilmiah DASI Vol. 17. No. 2 Juni 2016.

Roberts, A. 2003. Undang-Undang sistem pendidikan nasional Nomor 22,(1961). . [Online]. Available: http://simpuh.kemenag.go.id/regulasi/uu_22_61.pdf

Sehman, \& Anam, K. 2019. Penerapan Metode Forward Chaining Pada Perhitungan Kebutuhan Material Pembangunan Rumah Dan Pencarian Jasa Tukang Terdekat Berbasis Android. SEMINAR SANTIKA 4-5 SEPTEMBER 2019 ISBN : 978-6-02526748-2 . 